ing disappeared at the same time. No other consequence was felt besides a kind of nervous sensibility, disagreeable enough, which produced a shuddering and trembling at the slightest noise during an excursion, and induced great horror at even the sight of a dead snake.

Whether ammonia is useful against the bites of American snakes I do not know; little confidence is placed in it in the interior of America. Arsenic and corrosive sublimate are both celebrated in Peru and Colombia. But prevention is better than cure, and by an adequate clothing for the feet, and other little foresights, preservation from the ordinary possibilities of wounding may be ensured, as poisonous snakes in hot regions are nothing near so frequent as is generally supposed.

\section{CASE OF POISONING BY NUX}

\section{VOMICA.}

\section{By R. Dundas Thomson, M.D.}

THIs case formed the subject of an inquest before the late Mr. Stirling. A young girl, named Sarah Crabbe, was brought in a coach to the University College Hospital. Her head hung down when seated on a chair; the face was pale; the eyes open and bright; the arms flexible. On feeling the pulse, Mr. Taylor pronounced, to the surprise of those around, that the body was lifeless. The cheeks, from an ashy paleness, became, two or three days after, of the natural forid colour. It appeared, in evidence, that the deceased bad only been in the service of her master, a penmaker, a few days; she was then 18 years old, in excellent health, and very cheerful. About the middle of the week she came to him and said there was no butter; he gave her a shilling to procure some; as she did not return, his wife missed her at a quarter before nine. After this hour no tidings were heard of her till half-past seven in the evening, when her father-in-law, who said he was a distant relation, called with another respectable man, and examined the drawers in the kitchen. Among other things a powder was found, said to be burnt alum, a tumbler washed out with soap suds, and a pail in which she had vomited a greenish-yellow matter, quite different to anything seen in common sickness. The deceased had stated to a little girl, a cousin of her master, that on the previous day, before breakfast, she had mixed up some sugar of lead to do her gown with, and had swallowed it because she was thirsty. It appeared from the evidence further adduced, that she had formed an attachment to a young man at Dartford, who rather slighted her. Three weeks before she left her mother's house smartly dressed, had a new pair of boots on, and, without telling any one, walked all the way to Dartford to ascertain the cause of her sweetheart's silence. He was not prepared for the visit, procured a bed for her at a respectable inn, and sent her off, by a cart going to town, at 6 o'clock the next morn. ing. A nurse, who gave her evidence, stated that she had known the young woman nine months. She came to wituess's house, in Camden-terrace, at 10 o'clock (when she went ont for the butter); was very gay and cheerful; stopped the afternoon; said she came to take a cup of tea: talked over her future prospects; expected to be married very soon, and to go into business with a young man living in the conntry. About 4 o'elock she said, "I'll fetch some milk, nurse." She returned with it ; they dranktea, about 5 o'clock the nurse went to fetch in some clothes drying in the yard; on returning, the young woman was seated in a chair; the nurse said, "Why, Sarah, you appear drowsy." She answered, "I am," and then exclaimed, "Oh dear, how ill I am ; I have taken poison." She bad got it, she said, from the chemist's just by. The chemist admitted he had sold her a penny. worth of nux vomica, a little while before, to kill rats. On going back from the che. mist's, the nurse found her very ill indeed; left the landlady of the house to take care of her, and, after calling on four surgeons, found one who came to see hel, and gare her a powder which made her vomit, and yielded her some relief. She fell on the floor; struggled dreadfully, violevtly; ras placed on the bed; threw up a large quantity of blood, and nearly spoiled the bed. She was heard to exclaim, "Oh, what would I give to be saved!" In the coach she was very still and quiet, the vio. lent struggles were over; as she was cal. ried out of the coach she drew a deep sighher last. The verdict brought in was, "Poisoned herself in a state of temporary derangement."

Post mortem examination. (From $\mathrm{HI}$. Taylor's Note-book.)

The body fully developed, and exceed. ingly well-formed, covered with a thich layer of fat; pupils in the natural state; hair dark.

Head.-Dura mater presented, externally, several bloody points of considerable size; brain large; veins between the coavolutions very much distended; a rather considerable effusion of blood within the cavity of the arachnoid, lying on the upper surface of the convolution, especially in the right hemi. sphere. The congestion and effusion here were more marked than in more depending parts of the brain. Great congestion of the vessels of the pia mater; no liquid effusica under the arachnoid; the substance of the 
brain not so soft as might have been expected five days after death; cortical substance of a much deeper or browner gray than in healih; white substance, on incision, exhibited numerous large bloody points of a darker colour than in health; a little serum near the lateral ventricle; choroid plexus congested; corpora striata of deep gray colour; cerebellum presented signs of congestion similar to those of the cerebrum, especially rather dark colour of the gray substance.

Chest.-Heart normal, containing little blood; calibre of the aorta small, embracing the pont of the index finger soon after its exit from the heart; a little bloody serum in pericardium; lungs of a pretty uniform deep red colour, and tolerably filled with blood; a little bloody serum in left pleura; no sign of any disease in them.

Aldoinen.-Lower half only of oesophagus examined. For two or three inches the mucous nembrane considerably injected; then occurred an interval of paleness, after which it was red down to the termination. The stomach, of the usual size and form, contained a moderate quantity of fluid, in which, as well as adbering to its coats, was a considerable quantity of a darkish gray powder. The mucous membrane entire in its whole extent; not thickened; in its small curvature were lines of fine pink capilli-form injection; very considerable injection in the grand cul de sac, with many points of ecchymosis. The gray powder was adherent here in unusual quantity, as well as towards the pylorus, and which also presented similar morbid appearances.

Intestines, externally, of a red colour, apparently from imbibition; not further examined.

Spleen rather soft.

Liver and gall.bladder.-Nothing particular remarked.

Pancreas rather of a deep red colour.

Kidnies deep red, especially the tubular portion.

Bladder not examined; contains some urine.

Womb rather large; contained a good deal of gelati-form mucus. The mucous membrane, for half or three quarters of an inch from fundus downwards, considerably congested. Left ovary converted into a serous cyst; none of the normal structure remaining; right ovary, one corpus luteum.

Chemical Examination of the Contents of the Stomach.

The quantity of the contents of the stomach, obtained for analysis, amounted to about a fluid ounce. It possessed the consistence of treacle, and exhibited the appearance of digested animal food or chyme. A similar mixture may be produced by digesting muscle, cut into small pieces, in some dilute acids, at a temperature equal to that of the human body. This is a point of interest, because it did not appear from the eridence that any food had been taken during the whole of the day, up to four o'clock P.M. The nature of the cuntents of the stomach, however, demonstrate that animal food had been swallowed. The odour of the fluid mass was strongly acetous; litmus test-paper, when introduced into it, was immediately reddened. A similar effect was produced when a portion of the matter was brought in contact with a solution of litmus in distilled water.

About one half of the matter was introduced into a flask by means of a small tube terminating in a capillary aperture. The fluids thus mixed were boiled over a spirit. lamp for twenty minutes, two ounces of distilled water, acidulated with sulphuric acid, being previously added. It exhaled a strong smell of nutmeg; the whole was then thrown upon a filter; the solid matter* remaining on the filter was well washed with boiling distilled water. The liquid which passed through the filter was evaporated on the sand-bath, and mixed with some finely-powdered marble; the whole was reduced to dryness. This was pulverised and introduced into a flask; successive portions of alcohol were then boiled with it, until the spirit ceased to be colour. ed, and to afford a residuum on evaporation. The alcoholic solution was then filtered, the residuum washed, and the solution evaporated to dryness. The residue

* The residuum on the filter was a coarse whitish brown powder; a portion was heated on charcoal before the blowpipe. Sulphuretted hydrogen was evolved, and metallic globules were speedily produced, which cut like lead, being quite soft. To prove the nature of the metal still more distinctly, a small portion was placed in a watch-glass and covered with common aerated water. A white powder soon began to appear, which increased in quantity every day. It was soluble, with effervescence, in dilute nitric acid, showing that it was carbonate of lead. The powder, after digestion in water, was dried and exposed to the heat of a spirit-lamp; copions fumes of decomposed animal matter were evolved, and a gas was given out which caught fire and burned. A white powder remained, which, when treated by the process of reduction, was entirely converted into metallic lead. The various solutions and residue afforded no trace of the presence of alumina, showing that the alum, if any had been swallowed, had been carred away from the stomach, while the lead, which had been taken nine hours before death, still remained. A case is noticed in the German journals where lead was found in the stomach three days after it had been introduced into that viscus. 
occupied the bottom of the porcelain bason, lukewarm water. This treatment is neces. in the form of a thin brown coating, pos- sary, because the insoluble powder becomes sessing an intensely bitter taste, which deliquesced in the air; this matter was again dissolved in alcohol. When caustic ammonia was added to this solution brown lakes fell in abundance. With nitric acid a yellow characteristic solution was formed. When evaporated, the brown residue possessed a powerfully bitter taste. I then tried the effect of sulpho-cyanide of potas. sium, and obtained indistinet crystals, but not of such correct delineation as to warrant the praise which Artus has bestowed upon this test. The former characters, however, sufficiently demonstrate that the substance under examination was strychnin.

A solution of the strichnin in alcohol was introduced under the skin, on the back of a full-grown green linnet, and a small portion of the powder was placed in its mouth. The bird soon began to be spasmodically affected in the legs and wings, and after some time died with symptoms of convulsed legs and wings, and retraction of the head.

Remarls. - In reviewing the preceding case, there are some points which deserve notice in a medico-legal point of view.

1. The verdict. -W as it a logical deduction from the facts brought forward in evidence? We cannot decide that an individual is in. sane from one single isolated fact ; for insa. nity is a series of facts or acts properly inferred from an imaginary origin. There does not appear to have been anything analogous, as far as the evidence goes, in the instance under consideration, and no one could have been justified in even suspecting the unfortunate girl of insanity, from any act which she had committed previous to the last awful step of which she was guilty. When the poison began to act, she regretted her crime, which was certainly not characteristic of insanity. The rational explanation appears to be that she had formed an attachment which was only tem. porarily reciprocal. Having boasted to various individuals of her love, her vanity was galled by her inability to demonstrate to her friends any return of affection from her reputed lover; and having corresponded with him, and receiving no answer to her letters, she paid him a visit, which was not well received. This circumstance preyed upon her mind in her solitude, and she erro. neously reasoned that it was preferable for her to commit suicide than to survive an unreturned love and the taunts of her acquaintances. The cause of her crime was a false morality, not insanity.

2. The only treatment adopted was an emetic. In the absence of a stomach-pump, it was proper to have recourse to this palliative. But in every case where nux vomica has been swallowed, the stomach should be emptied of its contents completely, and then carefully and frequently washed out with mechanically adherent to the coats of the stomach, and requires repeated and some. what forcible efforts to remove it from its place. It is impossible to impress too strongly upon medical men the absolute necessity of their having always at hand this important instrument, and great readiness in its application.

3. The lead, which had been swallowed nine hours before death, was detected in the stomach in considerable quantity, showing that when a salt of lead enters into that viscus, it combines with the animal matter, and no longer exists in its original state, This subject I have discussed elsewhere at considerable length. (LANCET, volume II., 1837.38, p. 279.)

THE DUBLIN LYING-IN HOSPITAL AND

\section{DR. KENNEDY'S LECTURES.}

\section{To the Editor of The LANCET.}

SrR:-The remarks on the "System of Education pursued at the Dablin Lying.in Hospital" have amused me not a little; for having recently attended the practice of that institution I happen to know something of the matter. To that portion of your corre. spondent's letter which relates to the comfort and well-being of the patients, I hare nothing to object. It is also equally remote from my intention to question the opportuni. ties of practical observation which the cha. rity affords; but upon the "system of education" I shall trouble you with a little of my own personal experience.

I entered as a pupil of the above institu. tion in August, 1838, having been, in some measure, induced to do so by an advertise. ment (similar to those which appear from time to time in your widely-spreading Journal) in an English provincial paper, setting forth the opportunities, not merely, as it appeared, of practical observation, but also of scientific information, enjoyed by the pupils of the hospital. The advertise. ment stated that Dr. Evory Kennedy (the master) delivered four courses of lectures annually. It did not state that these lectures were chiefly upon cases occurring in the Hospital, or upon such subjects as might best suit the master's convenience; nor that their delivery was contingent upon the demands of Dr. Evory Kennedy's practice; nor, that in the event of his services being required by the lady of a noble lord, in a remote part of Ireland, the Doctor would attend that noble lord's noble lads, eren though his doing so might occasion his absence from Dublin for a whole fortnigbt, and the loss of six or seven lectures to his 